\title{
O GERME DA MUDANÇA OU A POSSIBILIDADE LATENTE DE RESISTÊNCIA À PERVERSIDADE DA GLOBALIZAÇÃO: UM ENSAIO A PARTIR DAS MÚSICAS DE DENÚNCIA ${ }^{1}$
}

\author{
Artur Monteiro Leitão Júnior ${ }^{2}$ \\ Dayane Zandonadi Soares ${ }^{3}$ \\ Vitor Ribeiro Filho ${ }^{4}$
}

\section{Resumo}

A globalização constitui-se, fundamentalmente, em um processo multidimensional, o qual, além de gerar transformações do Estado e da política, afeta diretamente a organização econômica, as relações sociais e os padrões de vida e cultura. Neste trabalho, buscou-se analisar músicas de diferentes estilos - rap, hip hop e reggae - sob o propósito de destacar certas formas de denúncia, mesmo que ínfimas, de toda a atuação massificadora e perpetuadora das condições precárias engendradas pelo movimento financeiro-cultural da mundialização. Essa denúncia evidencia-se enquanto uma forma de resistência cultural, própria da esfera local, abrindo novas possibilidades para a construção de um novo modelo de mundo.

Palavras-chave: Globalização; Música; Denúncia; Resistência.

\begin{abstract}
Globalization is fundamentally a multidimensional process that directly affects the economic organization, social relations and patterns of life and culture, as well generates transformations of the State and politics. In this work, we tried to analyze different styles of music - rap, hip hop and reggae - in order to emphasize certain types of complaint, even if minimal, of all the activities of massive and perpetuate poor conditions engendered by the movement of financial and cultural globalization. This complaint shows up as a form of

\footnotetext{
1 Artigo apresentado no módulo Globalização e Exclusão Social, como pré-requisito para a aprovação na disciplina Regionalização do Espaço Mundial do Curso de Geografia da Universidade Federal de Uberlândia UFU.

${ }^{2}$ Autor: Graduando do Curso de Geografia da Universidade Federal de Uberlândia e membro bolsista do Grupo PET Geografia - UFU. E-mail: artur_ml_junior@yahoo.com.br

${ }^{3}$ Co-autora: Graduanda do Curso de Geografia da Universidade Federal de Uberlândia e membro bolsista do Grupo PET Geografia - UFU. E-mail: ecodayane@yahoo.com.br

${ }^{4}$ Orientador: Professor Doutor do Instituto de Geografia da Universidade Federal de Uberlândia (UFU)
} 
cultural resistance in a local level, opening new possibilities for the construction of a new kind of world.

Key-words: Globalization; Music; Complaint; Resistance.

Introdução: o que temos a ver com a globalização?

O mundo possuía, em 2005, 6,5 bilhões de pessoas, segundo dados da Organização das Nações Unidas, apresentados no relatório World Population Prospects: The 2008 Revision. De acordo com as projeções, o total populacional mundial, em 2010, atingirá o nível de 6,9 bilhões de pessoas (ONU, 2009).

Vários desses "hóspedes" exercem, constantemente, relações entre si em múltiplas esferas. Essas relações, ainda que sejam obscurecidas por interações complexas e subterrâneas, não se evidenciando de modo claro e evidente, produzem e reproduzem o sistema socioeconômico. No sistema produtivo, diversos locais de produção se combinam sob a perspectiva de gerar um todo produtivo, expresso por uma mercadoria final: é o caso, por exemplo, de um automóvel de montadora japonesa, cujo aço é originário do Brasil, os componentes eletrônicos são fabricados na Coréia do Sul, os bancos de couro provêm da Argentina, o motor é de fabricação alemã e os trabalhadores, em grande parte, são originários de Cingapura.

Esse emaranhado de situações de troca de mercadorias, informações e serviços, muitas vezes envolvendo várias partes do mundo para um mesmo fim, preenche corriqueiramente o dia-a-dia dos cidadãos; é por isso, e sob essa mesma lógica, que se cunhou a denominação “cidadão-global". Todavia, essa cadeia tão extensa e de tal modo tão específica em suas exigências (como, no exemplo, o motor exclusivo da Alemanha ou os bancos de couro da Argentina), não é proporcionalmente reconhecida e/ou refletida.

Esse caráter de intensificação do intercâmbio entre os mercados e sistemas produtivos é bastante discutido nos meios acadêmicos, ainda que o mesmo seja, em grande parte, vulgarizado pelo senso comum sob o termo globalização. O processo de integração dos mercados financeiros, em decorrência do desenvolvimento das novas tecnologias da informação e da comunicação, e a intensificação dos fluxos de investimento e de capital em âmbito planetário - o que é entendido, pelos economistas, como mundialização (BENKO, 2002) - atinge outras instâncias além da esfera econômica, refletindo-se também nos campos social, político e cultural (ORTIZ, 1994; SANTOS, 2000; BENKO, 2002). 
Mesmo assim, nessa amplitude de inferências na vida lato sensu, são contínuas as reproduções dessa engrenagem globalizadora sem um trabalho intelectual argucioso de contraposição, já que, segundo Batista Jr. (1998), a globalização se configura como um mito intocável, um fenômeno ideológico nem sempre muito sofisticado, servindo a propósitos variados, como a venda de jornais, revistas e livros superficiais (plano editorial) ou a incorporação de países ingênuos e despreparados na malha dos interesses internacionais dominantes.

Diante dessa realidade de (des)ordem, buscou-se, neste trabalho, analisar músicas de diferentes estilos - rap, hip hop e reggae - sob o propósito de destacar certas formas de denúncia, mesmo que ínfimas, de toda a atuação massificadora e perpetuadora das condições precárias engendradas pelo movimento financeiro-cultural da mundialização.

É a partir dessas pequenas, mas incômodas críticas sobre o processo de globalização e suas consequências perversas, que novas evoluções da engrenagem globalizadora podem ser consideradas estratégicas: é o caso, por exemplo, da utilização das próprias técnicas e instrumentos de informação para denunciar e provar que os excluidos ainda estão vivos e capazes de refletir sobre a possibilidade de mudanças substanciais (SANTOS, 2000). É desse modo que "os de baixo" conseguem transmitir que ainda estão presentes e que devem ser ouvidos e respeitados.

De maneira geral, os estilos musicais analisados representam, em sua origem, a manifestação contrária à homogeneização cultural. Por conseguinte, formalizam o protesto às mazelas sociais (MAGRO, 2002; SILVA; SOARES, 2004; ZENI, 2004), principalmente àquelas diretamente envolvidas na realidade presenciada pelo grupo musical.

\section{O enigmático poder de ação do processo global}

Inevitavelmente, a contemporaneidade está inserida no fenômeno da globalização - o qual também pode ser denominado de mundialização. Segundo Benko (2002), o primeiro termo foi veiculado originalmente pelos anglo-saxões, sendo bastante utilizado nos países da América Latina. Tais termos, globalização e mundialização, embora enfaticamente utilizados por diversos intelectuais, sobretudo economistas, sociólogos, geógrafos, historiadores e filósofos, adquirem o estatuto de um processo que se encontra na raiz das principais dificuldades do período atual, funcionando como uma "causa" que, ainda que tenha nome, é ininteligível (BENKO, 2002). 
A dificuldade de distinção teórica entre os termos globalização e mundialização está diretamente correlacionada à dificuldade de separar dois processos que integram o mesmo fenômeno mundial da atualidade, ainda que ressaltadas as suas características (PIRES, 2005). Dessa maneira, enquanto, para Ianni (1996, apud PIRES, 2005, p.215), a globalização pode ser entendida pela

progressiva e inconclusa integração econômica assimétrica e desigual de mercados (que supera a idéia de Estados-nacionais, embora os mantenha como unidade política de referência), com a exclusão daqueles que, não dispondo de importância estratégica no novo cenário em construção, não devem se tornar empecilhos ao modelo de sociedade econômica mundial idealizada pelo capital internacional.

Consoante Benko (2002, p.45), a mundialização

designa a crescente integração das diferentes partes do mundo, sob o efeito da aceleração das trocas, do impulso das novas tecnologias da informação e da comunicação, dos meios de transporte etc. Refere-se, também, a processos muito específicos que, para uns, são um prolongamento de tendências antigas e, para outros, marcam um novo período.

Assim, pode-se entender que a globalização é um processo específico que se sucede no interior do processo de mundialização mais amplo - é, portanto, uma mundialização sob a perspectiva econômica. A mundialização, então, relaciona-se, de acordo com a Enciclopédia Barsa (2009), com o ato de mundializar - isto é, tornar mundial um fenômeno ou processo; por conseguinte, é um processo mais amplo, que envolve outras esferas para além da econômica. Nessa perspectiva, o processo de mundialização envolve, por exemplo, uma perspectiva claramente cultural (ORTIZ,1994).

Feitas essas considerações acerca de um trabalho intelectual de distinção entre os dois termos, é relevante destacar que, no presente artigo, os termos serão usados livremente como sinônimos: considerando que, muitas vezes, as perspectivas mais gerais da mundialização ocorrem na esteira do processo de globalização econômica, o termo globalização será usado em referência à mundialização tanto na esfera econômica, quanto nas esferas social, política e cultural.

Portanto, apesar da configuração de um paradigma essencialmente correlato de processos econômicos, como, por exemplo, a circulação de capitais, a ampliação dos mercados ou a integração produtiva em escala mundial, tem-se que a globalização ou mundialização designam também forte influência na esfera social. A respeito desta influência, podem-se citar a criação e expansão de instituições supranacionais, a universalização de padrões culturais e o equacionamento de questões concernentes à totalidade do planeta, 
incluindo o meio ambiente, o desarmamento nuclear, o crescimento populacional e os direitos humanos (MUÇOUÇAH, 1995, apud VIEIRA, 2000).

De acordo com Vieira (2000), essa nova ordem global acarreta transformações nos âmbitos da organização econômica, das relações sociais, dos padrões de vida e cultura, das transformações do Estado e da política.

Santos (2000), por sua vez, trata o processo de globalização como um modelo perverso e desigual, o qual seria mais adequado, segundo ele, ser denominado de "globalitarismo" ao reforçar as formas totalitárias de vida, emblematizadas pela fábula da aldeia global.

Nesse sentido, os efeitos e as contradições do processo de globalização estariam distribuídos em três faces (Cf. SANTOS, 2000): a primeira é apresentada pela publicidade, criadora de ilusões em que o mundo real é camuflado, uma vez que a máquina ideológica permite a continuidade do sistema; a segunda é a da perversidade, das contradições, da concentração de riquezas e da expropriação da grande maioria da população mundial, a qual busca a sobrevivência em meio ao contexto crônico de desemprego, da pobreza exponencial e da perda da qualidade de vida; e a terceira, e última face da globalização, é a possibilidade de um mundo "por uma outra globalização”, a partir das relações de solidariedade.

A perversidade sistêmica desse movimento está relacionada, ainda de acordo com Santos (2000, p.37), com

a emergência de uma dupla tirania, a do dinheiro e a da informação, intimamente relacionadas. Ambas, juntas, fornecem as bases do sistema ideológico que legitima as ações mais características da época e, ao mesmo tempo, buscam conformar segundo um novo ethos as relações sociais e interpessoais, influenciando o caráter das pessoas.

Assim, o movimento de globalização, engatilhado pelas forças exógenas da informação e dos mecanismos financeiros, produz uma necessidade constante relacionada ao consumo, mais do que de produtos, de padrões. Na esteira da tendência à homogeneização, o bem-estar e a felicidade humana são colocados em xeque, depositados em mercadorias a serem consumidas, que, tão logo adquiridas, perdem o estatuto da fantasiosa promessa de satisfação. O que se coloca em evidência, então, é a obsolescência programada, engendrada por uma rápida reposição/atualização de tecnologias e pelo prosseguimento da criação de promessas de felicidade, criando desejos - e, portanto, consumidores - antes mesmo de criar os produtos. 
Nos bastidores desse ciclo vicioso de produção e consumo, os atores principais são as grandes corporações financeiras e transnacionais, impondo suas vontades em um jogo político desigual, arbitrado por uma arma poderosa: a publicidade (SANTOS, 2000).

Toda essa engrenagem sistêmica, envolvendo transnacionais, empresas financeiras, consumo e publicidade, baseia-se num novo arquétipo da relação entre os países, em escala global: a dita nova Divisão Internacional do Trabalho. A esse respeito, Costa e PortoGonçalves (2006, p. 43) declaram que:

Com a rápida expansão da industrialização para alguns países periféricos (alguns denominados depois "semiperiféricos"), principalmente a partir dos anos 1950, houve uma complexificação muito maior dos espaços produtivos. Dessa forma, a nova divisão internacional do trabalho passou a ser baseada não estritamente nos setores da economia por tipo de produto, mas nos níveis tecnológicos de produção, nas formas de gestão e nas relações de trabalho dominantes, o que inclui, é claro, o valor dos salários pagos aos trabalhadores.

Esta divisão do trabalho possui como alicerces a informação, a biotecnologia e o capital financeiro. Os tecnopólos (centros sofisticados de pesquisa) configuram-se como espaços estratégicos de inovação e produção de novas tecnologias, as quais, por sua vez, demandam uma permanente qualificação da força de trabalho. Além desses espaços de comando, os distritos financeiros sofisticados de gestão - normalmente localizados no interior de "cidades globais" - bem como os "paraísos financeiros", dão sustentação ao capital financeiro. Em essência, é o controle do capital e da informação que define os países centrais e os periféricos (COSTA; PORTO-GONÇALVES, 2006).

A alteração do padrão de Divisão Internacional do Trabalho repercutiu na modificação da configuração dos sistemas produtivos: se antes a produção estava concentrada num espaço próprio, concentrador de todas as etapas produtivas, localizado no país-sede ou em outro país, o novo sistema produtivo é fundamentado na articulação de empresas mais ou menos especializadas e espacialmente longínquas - as empresas em rede. Nesse sentido, o

novo sistema produtivo depende de uma combinação de alianças estratégicas e projetos de cooperação ad hoc entre empresas, unidades descentralizadas de cada empresa de grande porte e redes de pequenas e médias empresas que se conectam entre si e/ou com grandes empresas ou redes empresariais (CASTELLS, 1999, p.114).

Apesar dessa nova organização econômica do sistema produtivo favorecer uma interdependência maior entre diferentes partes do mundo, houve, paralelamente, um distanciamento entre os países considerados opostos em relação aos extremos de desenvolvimento. Assim, as discrepâncias foram acentuadas, por exemplo, no que concerne à qualidade de vida e ao bem-estar social, sobretudo a partir do momento em que se demonstrou 
evidente a saturação do Welfare State, no contexto de crise a partir das elevações dos preços do petróleo, ocorridas em 1973 e $1979^{5}$.

Nesse sentido, Chesnais (2001) afirma que a mundialização, ao nascer da liberalização e da desregulamentação do mercado, liberou as tendências à polarização e à desigualdade, confirmadas pelas chamadas economias do arquipélago ${ }^{6}$ - isto é, as economias engendradas pela forte seletividade espacial dos investimentos financeiros e pelos investimentos diretos de grupos industriais beneficiados por meio das condições de mercado e facilidade de movimento de capitais.

Ainda segundo o mesmo autor, a homogeneização favorece a acentuação da heterogeneidade e a desigualdade das economias. Essa homogeneização é marcada pela mundialização do capital a partir de certos objetos de consumo e de modos ideológicos de dominação, os quais são veiculados pelas novas tecnologias e pela mídia (CHESNAIS, 2001).

Algumas mudanças na esfera de produção são esperadas em momentos de crise, a fím de atender, prioritariamente, os interesses dos grandes capitais. Isso pode ser exemplificado a partir da globalização atual, marcada por um forte cunho neoliberal, em que o enxugamento da máquina estatal é revestido pelas forças do próprio mercado. De acordo com Costa e Porto-Gonçalves (2006, p. 41),

as políticas neoliberais e de desregulamentação mundo afora nas décadas de 1980 e 1990 foram decisivas na consolidação desse processo, aliadas a um novo padrão tecnológico que permitiu a enorme aceleração das trocas de produtos, capital e informações, além de ter facilitado a própria circulação de pessoas.

Assim, sob a égide do capitalismo em sua configuração neoliberal, o processo de globalização tornou-se mais excludente e impositivo, já que há a formação constante de grupos marginalizados em decorrência do padrão de desenvolvimento vigente. Esse padrão torna-se cada vez mais exigente em seus moldes de consumo. Diante disso, são vários os modelos e feições de excluídos socialmente, uma vez que, para Rogers (1995, apud DUPAS, 1998, p.122) “a abordagem de exclusão social é em sua essência multidimensional, incluindo

\footnotetext{
5 Segundo o Relatório da ONU, "Situação Mundial 2005 - o problema da desigualdade", citado por Lamas (2005), a desigualdade mundial vem aumentando nas últimas décadas, apesar do aumento da riqueza disponível. $\mathrm{O}$ relatório trata a desigualdade não apenas como diferença de renda, mas também no que se refere à qualidade $\mathrm{e}$ acessibilidade a serviços sociais básicos (como educação e saúde), oportunidade de emprego, proteção dos direitos humanos e capacidade de decisão (ou seja, influência e representatividade no poder político). Um exemplo claro do aumento das desigualdades é o fato de que a renda per capita dos 20 países mais ricos triplicou nos últimos quarenta anos (passou de US\$ 11.417 para US\$ 32.339), enquanto, nos países mais pobres, aumentou apenas 26\% (indo de US\$ 212 para US\$ 267, em 2002); a razão da renda per capita dos países em desenvolvimento em relação aos países industrializados, entre 1980 e 2001, caiu de $18 \%$ para 12,8\%.

${ }^{6}$ Termo extraído de Pierre Velts, L'economia d'archipel, Paris, PUF, 1996.
} 
não só a falta de acesso a bens e serviços, mas também à segurança, à justiça, à cidadania, ou seja, relaciona-se às desigualdades econômicas, políticas, culturais e étnicas".

\section{As reações à globalização: a dialética global-local}

Em certa medida, o processo de globalização configura-se como um movimento complexo e dual: ao mesmo tempo em que pode ser considerado como uma ocidentalização dos valores culturais de nossos tempos, também fortalece, paradoxalmente, a proliferação de identidades locais. Em outras palavras, significa dizer que os povos modernos estão imbricados em uma incessante relação dialética entre tradição e tradução, buscando o conservadorismo das suas tradições particulares/singulares pari passu ao projeto de tentativa de transferência de sistemas simbólicos diversos, exógenos, que permitam a aceleração dos seus próprios desenvolvimentos social e cultural (MIRANDA, 2000).

Essa condição dualista da globalização pode ser mais bem apreendida, em termos geográficos, pelas relações entre as escalas do global e do local.

Segundo Ianni (1994), essas escalas - o local e o global - determinam-se reciprocamente, mesclando e tencionando singularidades, particularidades e universalidades. Sob essa perspectiva, Giddens (1991, apud IANNI, 1994, p.147) considera que: "A globalização pode assim ser definida como a intensificação das relações sociais em escala mundial, que ligam localidades distantes de tal maneira que acontecimentos locais são modelados por eventos ocorrendo a muitas milhas de distância e vice-versa”.

Essas relações entre o global e o local (e vice-versa) são evidências da dinâmica da des-equalização/diferenciação (HAESBAERT, 1999). Ainda que diversos autores entendam essa relação dinâmica segundo um modelo simplista e desproblematizado - o qual tende a associar o global aos processos de totalização e generalização/universalização, e o local aos processos de fragmentação e particularização/singularização - a questão evidencia-se de modo muito mais complexo: Robertson (1995, apud HAESBAERT, 1999) propõe o termo "glocalização", demonstrando um embate constante entre a face homogeneizadora e a face heterogeneizadora no âmbito dessa relação, corroborando o fato de que os processos globais "implantam-se" no local, de modo que este local jamais se configura como um simples reflexo do global, pois impõe condições para a realização da globalização; por outro lado, o local pode globalizar-se na medida em que expande pelo mundo determinadas características locais, produzindo a diversidade no âmbito do global e complexificando as características dessa escala mais ampla. 
A esse respeito, Ianni (1994, p.155-156) considera que:

O local e o global estão distantes e próximos, diversos e mesmos. As identidades embaralham-se e multiplicam-se. As articulações e as velocidades desterritorializam-se e re-territorializam-se em outros espaços, com outros significados. O mundo se torna mais complexo e mais simples, micro e macro, épico e dramático.

Sendo assim, o jogo entre global e local não se trata apenas de uma homogeneização a partir da globalização, aparando as desigualdades, nem de uma heterogeneização provinda de localismos diferenciados, marcados por um caráter de resistência: antes disso, se configura como uma relação em que as condições originalmente locais podem se tornar globais na mesma medida em que a globalização abre possibilidades para a re-criação ou reinvenção do local (HAESBAERT, 1999).

Isso significa dizer, segundo Miranda (2000), que o projeto de globalização amparado pela difusão acelerada da informação e pela eliminação do tempo e do espaço - não gera, por consequência, a completa padronização das culturas e das identidades:

Pelo contrário, não apenas antigas querelas identitárias se mantêm vivas, como multiplicam-se diferentes bolsões de identidades locais, de inspiração religiosa, étnica ou comportamental, reanimadas e fomentadas como maneira de resistir à introdução de novos modos identitários uniformizantes. A tendência para a cristalização e difusão de uma ou de algumas poucas linhas de força de alcance global surge como mais nítida no campo da economia do que no campo da cultura (MIRANDA, 2000, p.83).

É nesse sentido que o autor considera arquétipos diferenciados de identidade: ao lado de uma identidade instituída - caracterizada por seu caráter "oficial", verticalizado, legitimando a priori o padrão ou o código geral - manifestam-se diversas identidades instituintes, que vêm de baixo pra cima e conformam os indivíduos, o grupo e/ou a comunidade. Entre estas identidades, destacam-se duas: as de resistência, próprias de minorias étnicas e religiosas, alicerçadas no resgate e culto das origens; e as de projeto, as quais, além de abarcarem grupos minoritários, também dizem respeito a outros movimentos, como os ecológicos ou de defesa da condição feminina, sempre sob a perspectiva de elaboração de um projeto de futuro. A proposição desses projetos se pauta em novos modos de vida e novas visões de mundo, buscando a transformação da estrutura social (MIRANDA, 2000).

Nota-se, então, que a perspectiva da resistência sempre aparece em destaque na relação global-local ou na dialética do processo de globalização. Objetivada na mera reafirmação de um estatuto histórico pertencente a um grupo minoritário ou, mais do que isso, 
na busca por uma legitimação de um padrão de vida, essa resistência adquire um caráter fundamental e pertinente nesse momento histórico.

\section{Os instrumentos da resistência: uma breve consideração acerca das músicas de denúncia}

De certo modo, afirmar que as singularidades/particularidades não se configuram como instâncias subalternas vis-à-vis ao universal, na relação global-local, significa dizer ou instituir a permanência da importância do indivíduo frente ao mundo. Em outras palavras, o individual continua a ter voz, ou direito de expressão, ainda que o cenário seja outro e as relações de força tendam a reproduzir os valores ocidentais, naturalizados pelo processo de globalização.

Nesse contexto, a arte, enquanto manifestação íntima subjetivada, ganha um evidente estatuto de importância em sua função de deixar permitir o extravasamento do indivíduo para além das fronteiras do seu $e u$, reproduzindo suas percepções e sentimentos acerca de uma verdade, real ou imaginada. A arte - do latim Ars, significando técnica ou habilidade - é produzida, por conseguinte, a partir da percepção, emoções e idéias, com o objetivo de estimular estas instâncias de consciência em um ou mais espectadores. Nesse sentido, a música, enquanto uma manifestação artística, permite, entre outros efeitos, o transbordamento do eu para a sociedade, das inquietações mais particulares, destacando-se, sob esse olhar, as manifestações de denúncias acerca da realidade de vivência.

A música, então, se configura como um discurso. Segundo Fernandes (2007, p.18), enquanto discurso "Referimo-nos a aspectos sociais e ideológicos impregnados nas palavras quando elas são pronunciadas. [...] As posições em contraste revelam lugares socioideológicos assumidos pelos sujeitos envolvidos, e a linguagem é a forma material de expressão desses lugares". Segundo essa proposição, aqui assumida, o discurso não se refere à linguagem, à língua, ao texto ou à fala, mas necessita desses elementos linguísticos para ter uma existência material. No caso mais específico da música, portanto, as letras não são os discursos em si, mas são as expressões dos discursos. Ademais, é preciso destacar que a realização sonora musical, desde o arranjo à interpretação vocal, configura-se como portadora de sentidos (PARANHOS, 2002), e, portanto, é também expressão dos discursos.

Considerando o padrão de exclusão social, intensificado pelo processo de globalização, os discursos musicais, sobretudo nos países ditos em desenvolvimento, ou, talvez mais adequadamente, economicamente periféricos, assumem, muitas vezes, um caráter de denúncia da realidade vivida e das constantes situações de opressão, injustiça social e 
desigualdade socioeconômica vigentes na sociedade. Um exemplo é a música "Pátria que me pariu" (1997), do artista Gabriel, o Pensador:

Uma prostituta chamada Brasil se esqueceu de tomar a pílula, e a barriga cresceu

Um bebê não estava nos planos dessa pobre meretriz de dezessete anos

Um aborto era uma fortuna e ela sem dinheiro

Teve que tentar fazer um aborto caseiro

Tomou remédio, tomou cachaça, tomou purgante

Mas a gravidez era cada vez mais flagrante

Aquele filho era pior que uma lombriga

E ela pediu prum mendigo esmurrar sua barriga

E a cada chute que levava o moleque revidava lá de dentro

Aprendeu a ser um feto violento

Um feto forte escapou da morte

Não se sabe se foi muito azar ou muita sorte

Mais (sic) nove meses depois foi encontrado, com fome e com frio,

Abandonado num terreno baldio

Pátria que me pariu! Quem foi a pátria que me pariu!?

A criança é a cara dos pais mas não tem pai nem mãe

Então qual é a cara da criança?

A cara do perdão ou da vingança?

Será a cara do desespero ou da esperança?

Num futuro melhor, um emprego, um lar

Sinal vermelho, não dá tempo prá sonhar

Vendendo bala, chiclete...

Num fecha o vidro que eu num sou pivete

Eu não vou virar ladrão se você me der um leite, um pão, um vídeo game e uma televisão

Uma chuteira e uma camisa do mengão

Pra eu jogar na seleção, que nem o Ronaldinho

Vou pra copa vou pra Europa...

Coitadinho! Acorda moleque! Cê num tem futuro!

Seu time não tem nada a perder

E o jogo é duro! Você não tem defesa, então ataca!

Pra não sair de maca

Chega de bancar o babaca!

Eu não agüento mais dar murro em ponta de faca

E tudo o que eu tenho é uma faca na mão

Agora eu quero o queijo. Cadê?

Tô cansado de apanhar. Tá na hora de bater!

Pátria que me pariu!

Quem foi a pátria que me pariu!?

Mostra tua cara, moleque! Devia tá na escola

Mas tá cheirando cola, fumando um beck

Vendendo brizola e crack

Nunca joga bola, mas tá sempre no ataque

Pistola na mão, moleque sangue bom

E melhor correr que lá vem o camburão

É matar ou morrer! São quatro contra um!

Eu me rendo! Bum! Clá! Clá! Bum! Bum! Bum!

Boi, boi, boi da cara preta pega essa criança com um tiro de escopeta

Calibre doze na cara do Brasil

Idade catorze estado civil morto

Demorou, mas a sua pátria mãe gentil conseguiu realizar o aborto.

Essa música apresenta uma narrativa de um personagem anônimo, o qual, justamente por seu anonimato, representa não só um indivíduo, mas toda uma classe pobre, 
estatisticamente relevante, mas insignificante do ponto de vista político, a não ser quando se transforma em problema de segurança pública ou alvo de políticas governamentais afirmativas e/ou assistencialistas. Mais do que isso, narra o contexto de nascimento e reprodução da violência, que, individualizada na figura de um “João-ninguém”, inicia-se na concepção do protagonista, nascido de uma prostituta pobre, menor de idade e de frustradas tentativas de aborto.

Não é por acaso que a relação entre o Brasil e a prostituta é construída na primeira sentença da música: afinal, o país - que, por extensão, busca representar todos os países de igual situação de subdesenvolvimento ${ }^{7}$ e subordinação diante dos países capitalistas centrais vende-se para inserir-se no mundo, permitindo aos outros usufruir daquilo que é genuinamente seu e, desse modo, fica condicionado a uma situação de humilhação constante. Essa é a mesma noção que Chico Buarque de Hollanda e Francis Hime constroem em sua música "Vai Passar" (1984): "Dormia a nossa pátria mãe tão distraída/ sem perceber que era subtraída/ em tenebrosas transações". Sob essa perspectiva, a "pátria mãe gentil" se transforma na "prostituta desgraciosa e rude".

É este filho da "pátria", nosso protagonista: um órfão, indeciso se, por sua condição, segue o caminho do perdão ou da vingança, do desespero diante do presente ou da esperança de um futuro melhor. Nesse trajeto, ele tenta redimir-se do sofrimento e da pobreza a partir do trabalho informal, enquanto vendedor ambulante, ou ainda a partir da construção de um sonho de ascensão social pelo esporte - o qual, sobretudo no futebol, por vezes seleciona um pobre menino da periferia, lançando-o no fabuloso mundo do consumo e da opulência.

Essa realidade cruel banaliza a violência, de modo que, criado sob surras, o menino aprende apenas a ser rude, tornando-se usuário de entorpecentes e ingressando no narcotráfico, até que, no cotidiano da violência armada, da qual se torna vítima ou partícipe, morre ainda jovem, sob o signo de manutenção da ordem. Eis, então, o fim trágico: mais um aborto social de um jovem que morreu, por falta de condições dignas de vida, muito antes de falecer.

\footnotetext{
7 Sobre este termo, Pasquino (1998) considera a tese dualista, em que é possível explicar tanto o subdesenvolvimento interno quanto as diferenças em nível internacional: "Aceitando a tese que considera o desenvolvimento como conseqüência da expansão e da difusão de alguns estímulos nos mais diferentes setores da atividade humana, principalmente nos setores econômicos e sociais (encarados como setores rebocantes dentro das várias sociedades), o Subdesenvolvimento, quer a nível (sic) interno ou nacional, quer a nível (sic) internacional, pode ser entendido como fruto de uma difusão incompleta e imperfeita desses estímulos, que faz com que sempre existam bolsões ou zonas não atingidos por eles. O desenvolvimento acontecerá quando as barreiras que impedem a difusão destes estímulos forem derrubadas, barreiras formadas, na maioria das vezes, por dificuldades na comunicação e não apenas por falta de recursos” (PASQUINO, 1998, p.1225-1226).
} 
Entretanto, o artista Gabriel, o Pensador, a despeito das suas contundentes críticas sociais e morais, insere-se no universo artístico do rap $^{8}$ enquanto integrante da classe média; levando em consideração que o discurso é produzido no âmbito do lugar socioideológico ocupado pelo interlocutor (FERNANDES, 2007), a visão apresentada por este artista diferencia-se das visões de outros grupos inseridos nas classes sociais mais pobres, ainda que o caráter seja o mesmo: de denúncia.

Esse é o caso, por exemplo, da banda de reggae $e^{9}$ brasileira Tribo de Jah, formada por quatro integrantes cegos e outro com visão apenas parcial; ou ainda do artista português MC Xeg, classificado pela indústria fonográfica como cantor de hip hop ${ }^{10}$. Em relação à primeira, destaca-se, exempli gratia, a música “Globalização - o Delírio do Dragão” (1999), da qual segue o seguinte trecho:

Os dirigentes do sistema impõem o seu lema: livre mercado
mundo educado para consumir e existir sem questionar
não pensam em diminuir ou domar a voracidade
e sacanagem do capitalismo selvagem
com seus tentáculos multinacionais
querem mais e mais lucros abusivos
grandes executivos são seus abastados serviçais
não se importam com a fome, com os direitos do homem
Querem abocanhar o globo
dividir com poucos o bolo
deixando migalhas para o resto da gentalha

De maneira geral, a letra se apresenta de um modo mais explícito acerca da globalização, evidenciando a dinâmica da exclusão social no interior desse processo ao considerar os atores sociais responsáveis por esse perverso quadro de acentuadas desigualdades: as empresas multinacionais, individualizadas na figura dos grandes executivos. Nesse contexto, o sistema de produção capitalista normalmente aparece como o vilão fundamental e causador das condições de opressão e violência, uma vez que, na escala local e

\footnotetext{
${ }^{8}$ Segundo Zeni (2004), o rap (abreviação do termo inglês rythym and poetry, traduzido como "ritmo e poesia") resulta da junção de dois elementos do movimento hip hop: o DJ (disc-jóquei) e o rapper. Constitui-se, portanto, na parte musical deste movimento.

${ }^{9}$ Segundo a Enciclopédia Barsa (2009), o reggae é um "gênero de música popular da Jamaica, nascido em 1950 como forma local do rythm and blues com influências africanas e caribenhas".

${ }^{10}$ Conforme Zeni (2004, p.230): "O hip hop se constitui de quatro elementos: o break (a dança de passos robóticos, quebrados e, quando realizada em equipe, sincronizados), o grafite (a pintura, normalmente feita com spray, aplicada nos muros da cidade), o DJ (o disc-jóquei) e o rapper (ou MC, mestre de cerimônias, aquele que canta ou declama as letras sobre as bases eletrônicas criadas e executadas ao vivo pelo DJ). A junção dos dois últimos elementos resulta na parte musical do hip hop: o rap (abreviação de rythym and poetry, ritmo e poesia, em inglês). Alguns integrantes do movimento consideram também um quinto elemento, a conscientização, que compreende principalmente a valorização da ascendência étnica negra, o conhecimento histórico da luta dos negros e de sua herança cultural, o combate ao preconceito racial, a recusa em aparecer na grande mídia e o menosprezo por valores como a ganância, a fama e o sucesso fácil”.
} 
nacional, instaura relações díspares de exploração entre classes sociais e, na escala mundial, entre países centrais e países periféricos, como revela a percepção de Xeg, em sua música "O Sistema" (2004):

O mundo assiste à globalização, globalização da pobreza

E da injustiça social

$[\ldots]$

Porque é da miséria do terceiro mundo

Que é feita a riqueza do mundo Ocidental!

Em suma, as palavras de ordem do status quo que se observa giram em torno de noções antiéticas de um capitalismo selvagem, desumano e perverso: assim, o sistema (ou a globalização) se configura como instrumentos de disseminação da pobreza, da injustiça, da fome, da miséria - enfim, da exclusão social.

Entretanto, é justamente por meio dessa percepção explicitada que a classe pobre abre a possibilidade de expor inequivocamente a sua condição de subordinação e, mais do que isso, de expressar a sua consciência diante de tal realidade; nesse sentido, antes de uma resignação, essa classe busca a (re)construção do meio de vida, projeto do qual a arte - e, no caso, a música - é um instrumento fundamental. Talvez seja nessa perspectiva que Santos (2000, p.132) tenha declarado:

A pobreza é uma situação de carência, mas também de luta, um estado vivo, de vida ativa, em que a tomada de consciência é possível. [...] Eles [os pobres] descobrem cada dia formas inéditas de trabalho e de luta. Assim, eles enfrentam e buscam remédio para suas dificuldades. Nessa condição de alerta permanente, não têm repouso intelectual.

Identificando, segundo uma proposição aproximada e grosseira, a cultura dos pobres como cultura popular ${ }^{11}$, Santos (2000) indica uma possibilidade, cada vez mais frequente, de uma revanche dessa cultura popular sobre a cultura de massas:

\footnotetext{
11 Segundo Coelho (1997, p.118): “O conceito de cultura popular é, hoje, extremamente controvertido. As concepções do dedutivismo e do indutivismo sumarizam, em grande parte, as diversas correntes que discutem o tema. Para os dedutivistas, não há propriamente uma autonomia da cultura popular, subordinada que está à cultura da classe dominante, cujas linhas de força regem a recepção e a criação populares. Para os indutivistas, pelo contrário, a cultura popular é um corpo com características próprias, inerentes às classes subalternas, com uma criatividade específica e um poder de impugnação dos modos culturais prevalentes sobre o qual se fundaria sua resistência específica. Se para os dedutivistas, só se pode conhecer aquilo que é chamado de cultura popular a partir das lentes da cultura dominante, para os indutivistas somente é possível apreender a natureza dessa cultura mediante seus próprios depoimentos diretos, expressos em suas obras ou em declarações explícitas de seus produtores.

Entendimentos intermediários buscam apresentar a cultura, popular como um conjunto heterogêneo de práticas que se dão no interior de um sistema cultural maior e que se revelam, corno expressão dos dominados, sob diferentes formas evidenciadoras dos processos pelos quais a cultura dominante é vivida, interiorizada, reproduzida e eventualmente transformada ou simplesmente negada".
} 
[...] ela [a cultura popular] se difunde mediante o uso dos instrumentos que na origem são próprios da cultura de massas. Nesse caso, a cultura popular exerce sua qualidade e discurso dos "de baixo" pondo em relevo o cotidiano dos pobres, das minorias, dos excluídos, por meio da exaltação da vida de todos os dias. Se aqui os instrumentos da cultura de massa são reutilizados, o conteúdo não é, todavia, "global", nem a incitação primeira é o chamado mercado global, já que sua base se encontra no território e na cultura local e herdada (SANTOS, 2000, p.144).

Balizada na experiência e na solidariedade, consoante Santos (2000), essa cultura endógena, dos pobres, realiza-se segundo níveis mais baixos de técnicas, capital e organização, gerando produtos típicos que, ao invés de denotarem uma fraqueza, indicam a força de tais criações, nascidas em consonância com o território dos pobres e seu conteúdo humano. Assim, esses produtos das periferias tornam mais expressivos os símbolos dos pobres, expressos na fala, na música e nas relações de reciprocidade e solidariedade entre as pessoas (SANTOS, 2000).

\section{À guisa de uma conclusão: a "sociedade do espetáculo" versus uma nova sociedade}

Genericamente, a globalização se configura como um fenômeno múltiplo e que contém, em seu bojo, a diversidade, podendo levar a resultados diversos: desde o universalismo cultural até a formação de diversos tipos de resistência, passando pelas possibilidades de apropriações criativas desenvolvidas pelos indivíduos (MANCEBO, 2002). O que se supõe, segundo um esquema grosseiro, é a ânsia homogeneizadora de uma cultura de massas, segundo uma perspectiva vertical, conduzida "por um mercado cego, indiferente às heranças e às realidades atuais dos lugares e das sociedades" (SANTOS, 2000, p.143). Nesse sentido, essa cultura faz-se necessária enquanto instrumento imprescindível para o sucesso do mercado, expandindo o processo de globalização de ordem econômica, técnica, financeira e cultural. De acordo com Santos (2000, p.143-144), entretanto, "Essa conquista, mais ou menos eficaz segundo os lugares e as sociedades, jamais é completa, pois encontra a resistência da cultura preexistente", evidenciando que a cultura popular também reage, paralelamente; ele ainda completa: "Constituem-se, assim, formas mistas sincréticas, dentre as quais oferecida como espetáculo, uma cultura popular domesticada associando um fundo genuíno a formas exóticas que incluem novas técnicas”.

É com a "espetacularização" do cotidiano que se coloca em voga, então, uma questão crucial: a reapropriação dos desajustados, isto é, a inclusão dos críticos ao interior do sistema do qual fazem crítica, dando uma sensação de abertura democrática e direito de voz, quando, na verdade, seus discursos são esvaziados de conteúdo, embora lhes sejam permitidas as 
manutenções de suas formas. Esses desajustados - fazendo referência aos artistas críticos das questões de exclusão social e do processo sistêmico e estrutural de desigualdade engendrado pela globalização - acabam se constituindo em partes da engrenagem do sistema, o qual adota uma postura de modernização conservadora ${ }^{12}$.

Nesse sistema de concessões de crítica, o conteúdo fica subjugado à forma, e as críticas ao padrão vigente excludente são meramente escutadas - talvez somente porque a formalidade da "liberdade de expressão" obriga - mas não ouvidas, compreendidas e apreendidas. O mecanismo bem articulado do grande capital transforma a contestação em hit esporádico e efêmero, logo substituído por outro modismo de "rebeldia". Nessa lógica da mercantilização avassaladora, os discursos musicais se transformam em inania verba, isto é, palavras ocas, que divertem, mas, como os demais produtos, são logo descartados.

Todavia, essa pérfida apropriação não se concretiza em absoluto: apesar de domesticada, essa cultura da resistência ou da denúncia não é totalmente dissipada. O que se gera é um novo, pois a relação de crítica e apropriação silenciadora desta crítica é uma relação dialética, engendrando algo novo: uma cultura híbrida, sincrética, em que a crítica está posta e, mesmo que feita sob os auspícios da moda e do mercado, pode, no caminho, sensibilizar um ou outro. Essa nova cultura mesclada mantém em germe ou latência a possibilidade/vontade de mudança, e, nesse sentido, é possível crer que, mesmo debilitadas e incluídas em uma relação extremamente desigual de forças, as críticas e as concessões feitas aos críticos, em soma, possam ajudar a gerar algo novo, uma nova sociedade.

Condicionado à liberdade, o ser humano globalizado abre, ao menos em teoria, novos leques de opções de escolha, diante da diversidade de conhecimentos que obtém e de contatos que estabelece mediante essa nova era da velocidade e da informação. A liberdade possui um "instrumento", a inteligência, um "utensílio", a vontade, e uma "filha", a responsabilidade. A inteligência permite avaliar a escolha, configurando-se como uma liberdade de opção importante que só é levada a cabo a partir da vontade; feita a escolha, gera-se uma responsabilidade: assumir as consequências do que se escolheu (STEIGER, 1998).

Com a intensificação da exclusão social e o recrudescimento da massa de novos excluídos ou dos "de baixo", é preciso reavaliar nossas escolhas, entender nossas vontades e assumir novas responsabilidades. É ao menos esperançoso que, em meio a tantos artifícios de

\footnotetext{
${ }^{12}$ Esse termo é tomado emprestado de Barrington-Moore Jr. (citado em Carlos Nélson Coutinho - A democracia como valor universal, Ed. Ciências Humanas, São Paulo, 1978) por Moraes (2005), indicando que as relações de modernidade e de ingresso do Brasil na era do monopólio avançam em uma conciliação com as velhas estruturas, observando-se um alto grau de "transformismo" dos sujeitos políticos. Moraes (2005) também cita, sob o mesmo propósito, o termo revolução restauração, de Gramsci (citado em "As categorias de Gramsci e a realidade brasileira", Revista Presença, nº, São Paulo, 1986).
} 
abrandamento e vulgarização da crítica e da denúncia, a arte - expressa, por exemplo, nas músicas - ainda se manifeste embasada em um sentimento genuíno de contestação; talvez, então, chegue um momento (se é que já não chegou ou está em curso) em que a balança extremamente desigual da globalização se mostre não mais sustentável. É plausível que, nesse movimento, se pense ou se projete uma nova sociedade, alicerçada em novas lógicas.

\section{Referências:}

BATISTA JÚNIOR, Paulo Nogueira. Mitos da "globalização". Estudos Avançados, São Paulo, v.12, n.32, p.125-186, 1998.

BENKO, Georges. Mundialização da economia, metropolização do mundo. Revista do Departamento de Geografia, São Paulo, n.15, p.45-54, 2002. Disponível em: $<$ http://www.bibvirt.futuro.usp.br/index.php/content/download/297/1418/file/rdg15_10.pdf $>$. Acesso em: mar. 2009.

BOBBIO, Norberto; MATTEUCCI, Nicola; PASQUINO, Gianfranco. Dicionário de Política. Tradução: Carmem C. Varriale et al. 11.ed. Brasília: Editora Universidade de Brasília, 1998. v.1.

CASTELLS, Manuel. A economia informacional e o processo de globalização. In: . A

Sociedade em redes. São Paulo: Paz e Terra, 1999, p.87-117.

CHESNAIS, François. Mundialização: o capital financeiro no comando. Outubro. Revista do Instituto de Estudos Socialistas. n.5. São Paulo: Xamã, 2001.

COELHO, Teixeira. Dicionário Crítico de Política Cultural. 2.ed. São Paulo: Iluminuras Ltda, 1997. 384p.

COSTA, Rogério Haesbaert; PORTO-GONÇALVES, Carlos Walter. A des-ordem econômica mundial: a nova divisão internacional do trabalho. In: mundial. São Paulo: UNESP, 2006, p.31-50. A nova desordem

DUPAS, Gilberto. A lógica da economia global e a exclusão social. Estudos Avançados, São Paulo, v.12, n.34, p.121-159, 1998.

ENCICLOPÉDIA BARSA. 2009. Disponível em: <http://brasil.planetasaber.com>. Acesso em: mar. 2009.

FERNANDES, Cleudemar Alves. Análise do Discurso: Reflexões Introdutórias. São Carlos: Claraluz, 2007. 128p.

GABRIEL, O PENSADOR. Pátria que me pariu. In: GABRIEL, O PENSADOR. QuebraCabeça. Rio de Janeiro: Sony BMG, 1999. 1 CD. Faixa 1. 
TRIBO DE JAH. Globalização - O Delírio do Dragão. In: TRIBO DE JAH. Reggae na Estrada. 1999. 1 CD. Faixa 1.

HAESBAERT, Rogério. Região, Diversidade Territorial e Globalização. GEOgraphia, Niterói, ano 1, n.1, p.15-39, 1999.

HIME, Francis; HOLLANDA, Chico Buarque de. Vai Passar. In: HOLLANDA, Chico Buarque de. Chico Buarque. Rio de Janeiro: Polygran, 1984. 1 CD. Faixa 10.

IANNI, Octávio. Globalização: novo paradigma das ciências sociais. Estudos Avançados, São Paulo, v.8, n.21, p.147-163, 1994.

LAMAS, Bárbara Gomes. Aumenta a desigualdade mundial, apesar do crescimento econômico. Conjuntura Internacional, Belo Horizonte, v.19, p. 1-4, 2005.

MAGRO, Viviane Melo de Mendonça. Adolescentes como autores de si próprios: cotidiano, educação e Hip Hop. Cadernos CEDES, Campinas, v.22, n.57, p. 63-75, 2002.

MANCEBO, Deise. Globalização, cultura e subjetividade: discussão a partir dos meios de comunicação de massa. Psicologia: Teoria e Pesquisa, Brasília, v.18, n.3, set./dez.2002. Disponível em: <http://www.scielo.br/pdf/ptp/v18n3/a08v18n3.pdf>. Acesso em: dez. 2008.

MC XEG. O Sistema. 2004. (Música independente)

MIRANDA, Antonio. Sociedade da informação: globalização, identidade cultural e conteúdos. Ciência da Informação, Brasília, v.29, n.2, maio/ago.2000. Disponível em: $<$ http://www.scielo.br/pdf/ci/v29n2/a10v29n2.pdf>. Acesso em: nov. 2008.

ONU - ORGANIZAÇÃO DAS NAÇÕES UNIDAS. Divisão da População do Departamento de Assuntos Econômicos e Sociais do Secretariado das Nações Unidas. World Population Prospects: The 2008 Revision. Disponível em: <http://esa.un.org/unpp>. Acesso em: mar. 2009.

ORTIZ, Renato. Mundialização e cultura. São Paulo: Brasiliense, 1994.

PARANHOS, Adalberto. Vozes dissonantes sob um Regime de Ordem-Unida. Revista ArtCultura, Uberlândia, v.4, n.4, 2002.

PIRES, Giovani de Lorenzi. Globalização da economia/Mundialização da cultura. In: FENSTERSEIFER, Paulo Evaldo; GONZALES, Fernando Jaime (Orgs.). Dicionário crítico da educação física. 1.ed. Ijuí: Unijuí, 2005. p.215-218.

SANTOS, Milton. Por uma outra globalização: do pensamento único à consciência universal. 3.ed. Rio de Janeiro: Record, 2000. 175p.

SILVA, Vinícius Gonçalves Bento da; SOARES, Cássia Baldini. As mensagens sobre drogas no rap: como sobreviver na periferia. Ciência \& Saúde Coletiva, Rio de Janeiro, v.9, n.4, p. 975-985, 2004. 
STEIGER, André. Compreender a história da vida: do átomo ao pensamento humano. São Paulo: Paulus, 1998. 272p.

VIEIRA, Liszt. Cidadania e globalização. 4.ed. Rio de Janeiro: Record, 2000. 142p.

ZENI, Bruno. O negro drama do rap: entre a lei do cão e a lei da selva. Estudos Avançados, São Paulo, v.18, n.50, p. 225-241, 2004. 